\title{
A REVIEW AND EVALUATION OF INDIANA's INSPECT SYSTEM AND GOVERNING LEGISLATION: MAXIMIZING \\ Potential Impact on Public Health
}

\section{Jacob O'Brien"}

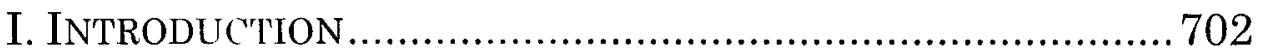

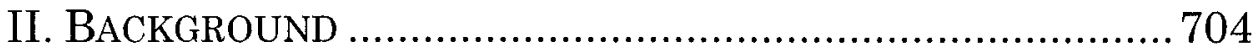

A. The Prescription Drug Problem ................................. 704

1. National Data ...................................................... 704

2. Indiana Data ..................................................... 708

B. Combating the Problem.............................................. 709

1. Differences in State Programs............................ 711

2. Additional Problems in Establishing and Developing PMPs ............................................. 713

3. Attitudes Concerning the Effectiveness of

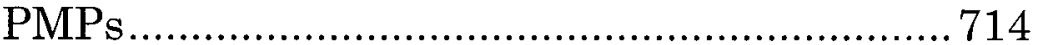

C. Indiana's INSPECT System.................................... 715

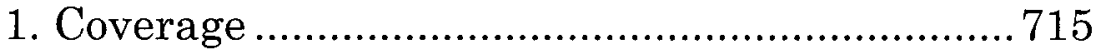

2. Authorized Users.............................................. 716

3. Access and Accuracy of Information.................. 717

4. Responsibilities and Liability Issues................. 718

III. ANALYSIS ................................................................. 719

A. Evaluating the INSPECT System ………………...... 719

1. Detecting and Preventing Abuse and Misuse ... 720

2. Promoting Proper Use....................................... 721

3. Informing the Public ......................................... 722

4. Evaluation of Impact.......................................... 723

5. Overall ........................................................... 723

B. Evaluation of Indiana PMP Laws.............................724

1. Some Positive Aspects......................................... 724

2. Some Shortcomings in the Law .........................725

C. Recommendations for Change …..............................727

1. Continue to Increase Number of Interoperability Agreements.....................................................728

2. Develop a More Proactive System ..................... 729

3. Create an Independent Evaluative Entity.........730

* J.D. Candidate, 2013 Indiana University Robert H. McKinney School of Law; B.S., 2009 Indiana University. 
4. Allow for Monitoring Non-Scheduled Substances 731

5. Require Practitioners to Consult the INSPECT

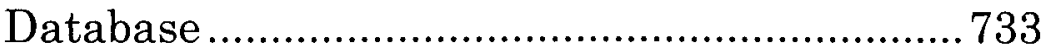

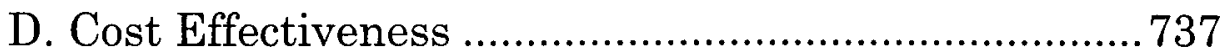

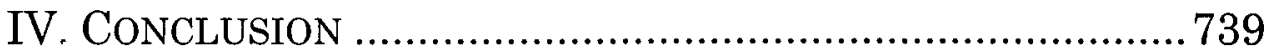

\section{INTRODUCTION}

Over the last couple of decades, the number of Americans injured or killed as a result of abuse and misuse of drugs has increased at an alarming rate. ${ }^{1}$ The largest source of this increase has come not from the use of illicit drugs, but, instead, from the abuse and misuse of prescription drugs. ${ }^{2}$ The vast array of drugs, developed with an intent toward treating the innumerable ailments from which people suffer, appears to have become something of an ailment itself, and the supply of prescription drugs is now as great as it has ever been. ${ }^{3}$ In just a relatively short time, prescription drug abuse and misuse has become one of the most pervasive problems facing health care systems across the country. ${ }^{4}$ In fact,

1 QuickStats, 59 MoRBIDITY \& MORTALITY WKLY. REP. 1009, 1026 (2010), available at http://www.cdc.gov/mmwr/pdf/wk/mm5932.pdf ("From 1999 to 2007, the number of U.S. poisoning deaths involving any opioid analgesic . . . more than tripled," reaching $36 \%$ of all poisoning deaths in 2007.).

2 See, e.g., Prescription Painkiller Overdoses in the US, VITAL SIGNS (CDC, Atlanta, GA.), Nov. 2011, at 1, 2, available at http://www.cdc.gov/VitalSigns/pdf/2011-11-vitalsigns.pdf (stating that "overdose deaths from prescription painkillers have skyrocketed" in recent years, and overdoses from the use of such drugs are now a "public health epidemic").

$3 \quad I d$.

4 See, e.g., Lisa Girion et al., Drugs Now Deadlier Than Autos; Fueled by Highly Addictive Prescription Pain Medications, Fatal Overdoses Have Surpassed Traffic Deaths Nationwide, L.A. Times, Sept. 18, 2011, at A1 (noting that the liberalized prescribing of pain drugs that began more than a decade ago may be the cause of the current epidemic). 
statistics now show that prescription pain and anxiety drugs are responsible for more deaths than heroin and cocaine combined. 5 Unsurprisingly, the states have responded. Forty-nine of the fifty states now have legislation in place allowing for the collection and supervision of prescription drug related data, with forty-two of those states having functional prescription drug monitoring programs. ${ }^{6}$ These prescription monitoring programs (PMPs) are seen as "highly effective tools utilized by government officials for reducing prescription drug abuse and diversion."7

Recognizing the gravity of this issue and the impact felt in its own state, the Indiana legislature created a body of law requiring the collection of controlled substance data in the mid-1990's, which led to the development of the INSPECT system in its current form in 2004.8 Although these efforts certainly reflect a movement in the right direction, injuries and deaths due to prescription drugs have continued to rise among Indiana citizens. ${ }^{9}$ While the INSPECT system certainly appears to be a useful resource in combating the prescription drug problem in Indiana, it may be the case that certain aspects of the system itself, and of its governing legislation, are limiting its ability to reach its full potential in this regard. In fact, under the current statutory scheme, there may actually be an incentive for non-dispensing practitioners to simply avoid using the INSPECT system at all. This paper is aimed at analyzing such shortcomings and exploring the feasibility of addressing them. The ultimate goal of this evaluation is to

\section{Id.}

6 Alliance OF States With PRescription MONITORING Programs, Prescription Monitoring Frequently ASKed Questions (FAQ) 1 (2012) [hereinafter PRESCRIPTION MONITORING FAQ], available at \%20FinalForPrint.pdf. http://www.pmpalliance.org/pdf/PMP\%20FAQ\%202012\%20-

$7 \quad I d$.

8 See generally IND. CODE $\S 35-48-7$ (2012).

9 See, e.g., CDC, POLICY IMPACT: PRESCRIPTION PAINKILleR OvERDOSES (2011), available at http://www.cdc.gov/Homeand RecreationalSafety/pdf/PolicyImpact-PrescriptionPainkillerOD.pdf (depicting death rates due to prescription drugs across the U.S.). 
promote more widespread use of the INSPECT system and to maximize the utility of the program.

\section{BACKGROUND}

\section{A. The Prescription Drug Problem}

\section{National Data}

In recent years, the United States has seen the number of deaths from most major preventable causes of death steadily decline. ${ }^{10}$ Perhaps the biggest and most worrisome exception to this trend has been the category of drug-related deaths. In March of 2011, preliminary data collected by the U.S. Center for Disease Control and Prevention showed that at least 37,485 deaths were related to drugs in 2009.11 This number is not only significant because of the sheer number of deaths, but also because it is greater than that of traffic related fatalities ${ }^{12}$ for the first time since data on drugrelated deaths began to be tracked. ${ }^{13}$ The preliminary data for 2010 indicated a continued increase in drug-related deaths, and once again the numbers were greater than those related to motor vehicle accidents. ${ }^{14}$

As mentioned above, the biggest source of what is now being referred to as an epidemic of drug-related injuries and deaths has come from the abuse and misuse of prescription

10 Girion, supra note 4.

11 Kenneth D. Kochanek, Deaths: Preliminary Data for 2009, NAT'L ViTAL STATISTICS RePS., Mar. 16, 2011, at 20, available at http://www.cdc.gov/nchs/data/nvsr/nvsr59/nvsr59_04.pdf.

12 Id. at 19 (reporting deaths at 36,284 ).

13 Girion, supra note 4.

14 Sherry L. Murphy, Deaths: Preliminary Data for 2010, NAT'L VITAL STATISTICS REPS., Jan. 11, 2012, at 19-20, available at http://www.cdc.gov/nchs/data/nvsr/nvsr60/nvsr60_04.pdf (reporting drug-related deaths at 37,792 and deaths from motor vehicle accidents at 35,080 and explaining that, while the drug-induced death rate declined from 2009 based on preliminary numbers, the actual number of such deaths may be substantially higher because of the delay in obtaining conclusive information about this particular cause of death). 
drugs, particularly in the form of prescription painkillers. ${ }^{15}$ In 2008, the number of deaths resulting from prescription painkiller overdoses alone had more than tripled in the years since 1999. ${ }^{16}$ In 2009, around 50,000 emergency room visits were related to prescription painkiller use, and the rate of admission to substance abuse treatment programs was nearly five times that in $1999 .{ }^{17}$ Such a surge in this misuse and abuse has led to health insurance providers now spending around $\$ 72.5$ billion annually on the associated costs. $^{18}$ If the trend continues to move as it has in recent history, this already staggering amount seems poised to continue to grow at an increasing rate.

Particularly troubling is the threat that prescription drugs pose to young people. There is data suggesting that teens abuse prescription drugs more than any illegal drug, with the only exception being marijuana. ${ }^{19}$ In 2008 , more

15 Leonard J. Paulozzi et al., Vital Signs: Overdoses of Prescription Opioid Pain Relievers United States, 1999-2008, Early Release, MORBIDITY \& MORTALITY WKLY. REP., Nov. 1, 2011, at 1, available at http://www.cdc.gov/mmwr/pdf/wk/mm60e1101.pdf.

$16 I d$. at 5 (demonstrating overdose deaths from opioid pain relievers from 1999-2010).

17 Id. From 1999-2008, the death rate from overdoses and the admission rate to substance abuse programs "increased in parallel." $I d$. at 3. Additionally, sales of opioid pain relievers in 2010 were four times greater than sales in 1999. Id. The statistics clearly demonstrate that although the number of people abusing these drugs has continued to increase significantly, these drugs are as readily available as ever.

18 Id. at 6; See also Join Together, Prescription Drug Abuse Leads to Higher Health Care Premiums, Fraud Group Says, THE PARTNERSHIP AT DRUGFREE.ORG (Feb. 27, 2012), http://www.drugfree.org/jointogether/prescription-drugs/prescription-drug-abuse-leads-to-higher-

health-care-premiums-fraud-group-says [hereinafter DRUGFREE.ORG] (explaining that " $[\mathrm{m}]$ ost of the cost comes from treatment, in the form of visits to the emergency room, rehabilitation, and associated health problems" and that a single person engaged in "doctor shopping" costs insurers between $\$ 10,000$ and $\$ 15,000$ ). When one considers that amount of people that are abusing these drugs, there is an almost undeniable implication that many of these people have engaged in "doctor shopping" in some way, and the costs that they impose on insurers is enormous.

19 Model Prescription Monitoring Program ACT § 2(d) (Nat'l Alliance for Model State Drug Laws, 2011) [hereinafter MODEL PMP], available at http://www.namsdl.org/documents/ModelPMPAct111911 
than 2.1 million teens aged 12 to 17 reported abusing prescription drugs. ${ }^{20}$ Unlike illegal drugs, young people need not even actively seek such prescription substances out for themselves. In 2010, the largest pharmacy-benefit manager in the U.S., Medco Health Solutions Inc., claimed that more than 25 percent of kids and teens take a medication on a chronic basis and almost seven percent of them are taking two or more drugs. ${ }^{21}$ Additionally troubling is the fact that many of the drugs being taken by these young people are drugs that have been considered appropriate for use only by adults in the past. ${ }^{22}$ When compounded with the fact that data exists suggesting that "90 percent of prescription drugs addictions start in teenage years," the recent trend becomes particularly alarming. ${ }^{23}$ Considering the amount of resources that the U.S. has spent on efforts to keep drugs out of the hands of children, the fact that such a significant portion of this country's youth has many drugs readily accessible to it is particularly discouraging. Children and teens no longer need to seek out a drug dealer, or even raid their parents' medicine cabinet. To gain access to many drugs, young people need only open their own medicine cabinets, or alternatively, simply ask

withoutcommentary_001.pdf. A number of other, more general findings are also quite significant. For example, the number of people abusing prescription drugs exceeds the sum total of all people who use cocaine, heroin, hallucinogens, ecstasy, and/or inhalants. Id. at $\S 2(\mathrm{~b})$. The Act also finds "little indication that the death toll [from abuse of such drugs] is abating." Id.

20 Id. (adding that, in 2006, this age group also accounted for onethird of all new prescription drug abusers).

21 Anna W. Mathews, So Young and So Many Pills, WaLl ST. J., Dec. 28, 2010, at D1, available at http:/online.wsj.oom/articlel SB10001424052970203731004576046073896475588.html?mod=WSJ hpp_editorsPicks 1 (last visited May 26, 2013) (attributing the increase in prescription drug use among young people to both increased awareness of drugs as an option for kids and a general lack of healthy dietary habits and exercise among young people).

22 Id. (identifying statins, diabetes pills, and sleep drugs as examples).

23 Legally Dead: Exploring the Epidemic of Prescription Drug Abuse, REHABS.COM, (last visited February 19, 2013), http://www. rehabs.com/explore/prescription-drug-abuse-statistics/. 
the one in four of their peers with such access to open theirs.

Adding to the complexity of the prescription drug problem is the propensity for many prescription drugs to interact dangerously with other substances. ${ }^{24}$ This includes other types of legal drugs, whether they are over-thecounter or require a prescription. When one considers the number of prescriptions being written in the U.S., the enormous scope of this problem comes into focus. In 2007, the Institute for Safe Medication Practices issued a report claiming that two of every three patients that seek out a doctor for care receive at least one prescription as a result. ${ }^{25}$ With the continued discovery and development of new drugs for a growing number of recognized and treatable ailments, it is likely that this ratio has increased in the years since that report. In addition, the U.S. Food and Drug Administration has stated that the likelihood of an adverse, potentially dangerous drug interaction increases drastically when a patient is taking more than three medications at once. ${ }^{26}$ When this is coupled with the fact that around forty percent of the U.S. population has four or more prescriptions, there is an almost undeniable implication that dangerous drug interactions contribute significantly to the prescription drug epidemic in this country. ${ }^{27}$

24 Avoiding Drug Interactions, Archive of Consumer Updates, FDA, http://www.fda.gov/ForConsumers/ConsumerUpdates/ucm096386. htm (last visited May 17, 2013). In addition to potentially interacting with different types of drugs, many prescriptions also have the potential to interact adversely with many types of supplements, foods, and drinks. Id.

25 Id.

26 Id. Although many drugs are now known to interact adverse-ly when taken together, most of these drugs are not withdrawn from the market. In fact, "market withdrawal of a drug is a fairly drastic measure" and "[m] ore often, FDA will issue an alert warning the public and health care providers about risks as the result of drug interactions." Id. This makes keeping track of prescription information all the more important.

27 Id. 


\section{Indiana Data}

Indiana has been no exception to the national prescription drug trend. In November of 2011, the CDC published a report illustrating that 13.2 of every 100,000 Hoosiers died from some type of drug overdose in 2008. ${ }^{28}$ Unsurprisingly, the data suggests that as the sales of these drugs increase in Indiana, so too does the number of people abusing or misusing them, which in turn increases the incidents of injury and death. ${ }^{29}$ As with the national trend, a majority of these deaths and injuries were related to prescription drug use, with opioid painkillers being the largest contributor. ${ }^{30}$ But painkillers are not the only prescription drugs being abused. For example, Adderall appears to be a drug that is abused and misused with significant frequency, particularly among college students. ${ }^{31}$ It is likely that these numbers only begin to reflect the true scope of the problem these institutions face, as only a small sample of students participated in the survey. Nevertheless, they demonstrate the continued emergence of prescription drug use in different settings.

With respect to cases of innocent or accidental misuse of drugs specific to Indiana, there is a very limited amount of data available. This may be due to issues related to the way this type of data is collected. Many such incidents are simply classified generally as an overdose, and are not necessarily reported, statistically speaking, with reference to the drug that caused the overdose. What the data that is

28 Paulozzi et al., supra note 15 , at 4.

29 See id.

30 Id. at 1; see also Legally Dead, REHABS.COM, http://www. rehabs.com/explore/prescription-drug-abuse-statistics/ (last visited May 17,2013 ) (stating that pain relievers are the cause of or a contributing factor to almost 3 out of 4 prescription drug overdoses).

31 ROSEMARY KING \& MI KYUNG JUN, INDIANA COLLEGIATE ACTION NETWORK, REsults of THE INDIANA COLlEGE SUBSTANCE UsE SURVEY 11 (2011), available at http://www.drugs.indiana.edu/publications/ icsus/ICSUS_Survey_2011.pdf. It is important to note, however, that only $12.6 \%$ of students invited to participate in the survey responded. Id. at 4 . Clearly the results of this study are limited, and it is probable that the data collected only reflects the tip of the proverbial iceberg. 
available suggests is that when compared to the age adjusted death rate of prescription drug injuries and deaths in other states, Indiana is close to the middle of the pack. ${ }^{32}$ Considering the seriousness and pervasiveness of the prescription drug issue, as illustrated in the discussion above, the problem in Indiana is clearly not under control; the Indiana legislature and health care practitioners must strive for improvement with regard to these numbers.

\section{B. Combating the Problem}

In an effort to bring the explosion of the prescription drug problem back under control, the states began developing prescription drug monitoring programs (PMPs) as early as 1939 in California. ${ }^{33}$ As mentioned above, fortynine of the fifty states now have legislation allowing for the collection of prescription data, and forty-two actually have functional PMPs. ${ }^{34}$ These programs generally collect data about prescriptions that involve federally controlled substances, and have the general purpose of assisting authorized PMP users in identifying problematic prescriptions in the hopes of deterring and reducing the abuse and misuse of drugs covered by the respective system. ${ }^{35}$

32 See Paulozzi et al., supra note 15 (including data showing that the Indiana overdose death rate is about 13.2 per 100,000 , which exceeds the national rate of 11.9 per 100,000 by a considerable margin and clearly suggests that further efforts toward combating prescription drug abuse in the state of Indiana are warranted).

33 Karen Blumenschein et AL., Review of PREscription Drug MONITORING PROGRAMS IN THE UNITED STATES 2 (2010), available at http://chfs.ky.gov/NR/rdonlyres/85989824-1030-4AA6-91E1-7F9E3EF68827/ 0/KASPEREvaluationPDMPStatusFinalReport6242010.pdf. See also Aarron M. Gilson et al., Time Series Analysis of California's Prescription Monitoring Program: Impact on Prescribing and Multiple Provider Episodes, 13 J. OF PAIN 103 (2012), available at http://www. painpolicy.wisc.edu/sites/www.painpolicy.wisc.edu/files/Gilson_2012_A\% 20 time $\% 20$ series.pdf (describing the characteristics and framework of the earliest monitoring program developed in California).

34 PRESCRIPTION MONITORING FAQ, supra note 6.

35 BLUMENSCHEIN ET AL., supra note 33. 
One significant goal of these programs is to prevent individuals from obtaining an amount of a given drug that exceeds their actual need through the use of "doctor shopping". ${ }^{36}$ "Doctor shopping" describes a situation in which an individual seeks out multiple prescription providers and dispensers in order to procure as much of a particular drug as possible. This can also allow an individual to obtain prohibited combinations of drugs that may create significant health risks if taken simultaneously. To aid in preventing this phenomenon, many states allow law enforcement to access their PMPs in relation to drug investigations. ${ }^{37}$ Additionally, many PMPs share prescription data across state lines, further assisting in the detection of doctor shopping. 38

The above information clearly illustrates that the overarching purposes of the PMPs in the states that have them are substantially the same. As one would expect, these programs share some essential aspects in attempting to achieve their objectives. However, in spite of these general similarities, there is significant variation in secondary goals and additional means of achieving them across the states. Understanding these differences is an important step in attempting to improve upon the effectiveness of any state PMP, especially as many states become increasingly willing

36 Id.; see also DRUGFEE.ORG, supra note 18 (providing a loose definition of the term and discussing the costs that individuals engaging in such activity impose on society).

37 BLUMENSCHEIN ET AL., supra note 33 (explaining that this allows law enforcement to "more efficiently collect and analyze data that may be useful in identifying those individuals involved in trafficking or misuse of prescription drugs").

38 See, e.g., NABP PMP InterConnect Celebrates One Year of Connecting Prescription Monitoring Programs to Combat Prescription Drug Abuse, NABP.NET, (Aug. 16, 2012, 12:34 PM), http://www.nabp. net/news/nabp-pmp-interconnect-celebrates-one-year-of-connectingprescription-monitoring-programs-to-combat-prescription-drug-abuse [hereinafter NABP.NET] (describing not only the general aspects of the program, but also some details into how the program deals with the "unique access and usage requirements" of the various state programs). It is noteworthy that NABP covers all costs associated with developing and operating the program without government funding. Id. 
and able to share prescription information across state lines.

\section{Differences in State Programs}

Although the fact that the vast majority of states have established PMPs is of considerable importance in combating the prescription drug problem, the existence of numerous systems has created problems of its own. Each state is charged with the choice of whether and by what means to establish a monitoring program, and not all states take the same approach. ${ }^{39}$ Considering the doctor shopping efforts of many individuals discussed above, this can become problematic when such individuals cross state lines to obtain drugs. In an attempt to reduce these differences and provide for more uniform programs, the National Alliance for Model State Drug Laws (NAMSDL) developed a model that sets forth the key characteristics of a strong PMP. 40 Additionally, a growing number of states are making efforts to achieve agreements of "interoperability" between their respective program and the programs of other states, which allow for the sharing of prescription drug data across state lines. ${ }^{41}$ Despite these efforts, the differences between the programs across the states and their respective PMP laws remain an obstacle in the ability of the states to prevent interstate doctor shopping.

Existing state PMPs differ in a number of respects. For one, many states' programs are run by their respective boards of pharmacy, but some are run by other entities, such as professional state licensing boards or law

39 See generally BLUMENSCHEIN ET AL., supra note 33, at 6-7 (noting information reflecting some differences in state programs in Table 1: Prescription Drug Monitoring Program Characteristics by State).

40 See generally Model Laws, NATIONAL ALLIANCE FOR ModeL STATE DRUG LAWS, http://www.namsdl.org/modellaws.htm (last visited May 17, 2013) (stating that links allow the suggested prescription drug laws pertaining to various issues to be viewed accordingly).

41 See generally BLUMENSCHEIN ET AL., supra note 33 , at 6-7; see also NABP.NET, supra note 38. 
enforcement agencies. ${ }^{42}$ These differences may reflect the varying goals of the states, with some appearing to take a punitive approach, and others a more preventative approach. Another common difference among PMPs can be found in which schedules of controlled substances the programs cover. ${ }^{43}$ Some states even go so far as to allow for the collection of certain non-scheduled substance data in certain instances. ${ }^{44}$ Additionally, states differ in which groups are allowed to access PMP information. ${ }^{45}$ For example, a state's PMP laws may allow personnel of certain licensing boards to access the information within their monitoring program, while other states may choose to exclude them. ${ }^{46}$ The same is true with respect to law enforcement officials. ${ }^{47}$ States also differ in how they approach the production of program reports for authorized users, but most programs produce the informational reports on a reactive basis, ${ }^{48}$ although there is probably a widespread desire for more proactive systems. Another crucial difference in state PMPs is in the approach to liability issues. Some states effectively bar any prescriber or dispenser from liability with regard to referencing prescription data. 49 In some instances, this even means

42 BLUMENSCHEIN ET AL., supra note 33, at 6-7 (demonstrating that, although there are clearly some exceptions, most programs are overseen by the respective state's board of pharmacy).

$43 \quad I d$.

44 Id. at 8 (see Figure 3). But, in some states, additional regulations may be necessary prior to initiating actual monitoring of non-controlled substances. Id at 7.

45 Id. at 13-20 (organizing the various approaches states have taken with respect to groups authorized to access PMP information and demonstrating that, while there is significant overlap, distinctions can clearly be made between states).

$46 \quad I d$.

$47 \quad I d$

48 Id. at 20 . Note that, at the time the report cited was issued, a number of states did not have programs that were at an advanced enough stage to have proactive reports.

49 Id. at 9; see also, e.g., IND. CODE $\S 35-48-7-11.1$ (2012) (Currently, Indiana does not require non-dispensing practitioners to reference PMP data. However, there was a bill being considered during the drafting of this note that may change this. This is discussed in greater detail below.) 
that there is no requirement that such practitioners even reference the program's prescription information at all before issuing a prescription. ${ }^{50}$

\section{Additional Problems in Establishing and Developing PMPS}

Beyond the differences in PMPs and their governing legislation, there are a number of other issues that the states must address in forming their respective programs. One such issue lies in the desire to create a program that produces the most current and reliable prescription data reports possible. Many states have expressed a need to develop such a real time program in which data is entered directly into the system and is available for reference immediately, but as of yet, not one state has succeeded in this regard. ${ }^{51}$ Another obvious issue is that of maintaining confidentiality. Because these programs collect personal health information of a given individual, significant measures must be taken to ensure that the privacy of such information is protected. These measures can contribute significantly to the complexity in operating the program, as well as the associated costs. ${ }^{52}$

Further problems are sourced in the fact that not everyone agrees that PMPs are worth the trouble when it comes to combating prescription drug abuse. Many opponents of PMPs have expressed concern that such programs lead to prescribers becoming less willing to make prescriptions for drugs covered by the program. ${ }^{53}$ This, they

50 Id. at 9-10. Although non-dispensing practitioners are not currently required to access PMP data in Indiana, dispensing practitioners are required to refer to this information, as will be discussed in greater detail below.

51 Id. at 13-20 (showing that, currently, even the fastest pro-grams' information may have a lag time of several days to a week).

52 See generally $i d$. at 10-12 (mentioning many factors, all of which can complicate the issue of states making sure that the information contained in their PMP databases remains secure).

53 Pilar Kraman, Drug AbUse in America - Prescription Drug DIVERSION, COUNCIL OF STATE GOV'TS 12 (2004), available at http://www.csg.org/knowledgecenter/docs/TA0404DrugDiversion.pdf 
argue, has an adverse effect on the overall quality of patient care because some may not receive all, or any, of the drugs that they need. ${ }^{54}$ Such concerns may provide some explanation as to why some states bar liability on practitioners for failure to utilize PMP data. Although this argument appears to make logical sense, the fact is that the data being collected regarding the amount of prescriptions given and the number of people consuming them seems to indicate that this "chilling effect" is more of a theory than a reality. ${ }^{55}$ Nevertheless, it is something that certainly must be considered in forming PMPs and their respective laws, as overall quality of care should not be threatened or harmed in this process. Prescribers must be informed about the purposes of the programs and how to view them as a tool rather than an obstacle to administering care.

\section{Attitudes Concerning the Effectiveness of PMPS}

Despite the fact that only a few states have conducted an evaluation on the impact of their respective programs in any official manner, the general attitude among states with operating PMPs is that the programs have had a positive impact in hindering the ability of individuals to abuse and misuse prescription drugs. ${ }^{56}$ For the states that have officially evaluated their programs, the finding has been that doctor shopping has become more identifiable, and thus preventable, thanks to these programs. ${ }^{57}$ However, in spite

(While "[s]ome reports have suggested that states with PDMPs have seen 35 to 50 percent reductions in the prescribing of regulated controlled substances, ... the overall production of Schedules II and III narcotics has steadily increased" in recent years.).

${ }_{54}$ Id. Although the argument is certainly worthy of consideration, the continued increase in production and consumption of scheduled substances certainly weighs heavily in favor of continuing to track such information through PMPs. As the article suggests, the best remedy for this "chilling effect" is probably education of practitioners, as well as patients. $I d$.

55 Id.; see also, e.g., Paulozzi, supra note 15.

56 BLUMENSCHEIN ET AL., supra note 33 , at 20.

57 Id. at 20-23 (reporting that valuations of the PMPs in Maine, Virginia, and Kentucky all indicated the presence and use of the 
of this positive response, the fact remains that consumption of controlled drugs has continued to rise, and with it, the number of injuries and deaths from such consumption. 58 While this certainly helps to counter the argument of opponents regarding the chilling effects of PMPs, it also indicates that perhaps more must be done in states seeking to maximize the impact of these programs.

\section{Indiana's INSPECT System}

The Indiana Scheduled Prescription Electronic Collection and Tracking (INSPECT) Program was created in its current form in 2004 as a means of collecting prescription drug information in accordance with Indiana legislation passed in the mid 1990's regarding such data.59 The expressed goals of the Indiana legislature in the operation of the system are to provide patient information storage for health care professionals and provide a resource for controlled substance investigations of law enforcement. 60 In addition, the legislature has clearly expressed that in no way is INSPECT meant to limit doctors in their treatment methods, nor is it meant to compromise privacy rights of Indiana citizens in any way. ${ }^{61}$

\section{Coverage}

In 2005, the scope of INSPECT was expanded from covering only schedule II substances to covering data on schedules II, III, IV, and V. ${ }^{62}$ Indiana is not currently among the states that have provided statutory authority for the collection of non-scheduled substances under any

respective state program helped at least to some considerable degree to combat doctor shopping).

58 Paulozzi, supra note 15.

59 About INSPECT, IN.GOV, http://www.in.gov/pla/inspect/ (last visited May 20, 2013); see also IND. CoDE $§ 25-1-13$ (2013).

60 About INSPECT, supra note 59 (adding that considerable measures are taken to "prevent abuse and ensure the confidentiality of patient medical records and other privileged information.").

61 Id.

62 See IND. CoDE $\S \S 35-48-7-2.5$ to -10 (2012). 
circumstances. ${ }^{63}$ When a substance covered by the INSPECT system is distributed to a patient, the dispenser must submit certain information pertaining to the transaction into the INSPECT system, including the name of the individual, the identity of the substance being distributed, and the quantity and number of days supply the individual is receiving. ${ }^{64}$ This monitoring is intended to provide authorized viewers with the necessary information to identify situations of potential abuse or misuse of monitored substances.

\section{Authorized Users}

The operation of the INPSECT system is overseen by the Indiana Board of Pharmacy. ${ }^{65}$ Additionally, there are a number of other groups authorized to access the system's prescription data.66 Some groups authorized to access the prescription information include law enforcement, state toxicologists, and certified Medicaid representatives. ${ }^{67}$ With respect to prescribers and dispensers, the law authorizes a "practitioner or practitioner's agent" to access prescription data. ${ }^{68}$ Included within the definition of "practitioner" are physicians, pharmacists, hospitals, and several other categories of healthcare related individuals. ${ }^{69}$

Additionally, Indiana law allows for INSPECT data to be shared with PMPs of other states with which an agreement of interoperability has been reached. ${ }^{70}$ Indiana has been among the leading states with respect to interstate sharing of prescription data since it began sharing such information with Ohio in 2011.71 Now, Indiana is sharing its INSPECT data with numerous other states. As a member of the

63 See id; see also BLUMENSCHEIN ET AL., supra note 33 , at 8.

64 IND. CODE $\S 35-48-7-8.1$ (2012).

65 IND. CODE $\S \S 35-48-7-8.1,12.1$ (2012); see also IND. CoDE $\S 35-$ 48-1-6 (2012) (defining "board").

66 See IND. CODE $§ 35-48-7-11.1$ (2012).

67 Id.; see also BLUMENSCHEIN ET AL., supra note 33, at 14-15.

68 IND. CODE $\S 35-48-7-11.1(\mathrm{~d})(4)(2012)$

69 IND. CODE $§ 35-48-7-5.8$ (2012).

70 IND. CODE $\S 35-48-7-11.1(\mathrm{~d})(5)$ (2012).

71 About INSPECT, supra note 59 (click "Inspect At-A-Glance"). 
National Association of Boards of Pharmacy's (NABP) InterConnect program, Indiana can now share prescription data with all of the following states: Arizona, Connecticut, Kansas, Michigan, North Dakota, Ohio, South Carolina, and Virginia. ${ }^{72}$ The presence of a growing number of state PMPs will place pressure on doctor-shoppers to cross state lines in order to procure their desired drugs, and forming more agreements of interoperability will become crucial in deterring such efforts.

Although it may seem obvious that individuals should be authorized to access their own INSPECT report, the legislation regarding authorized users does not directly address this issue. A fairly recent Indiana Court of Appeals decision resolved this, holding that individuals may request access to their personal INSPECT reports in certain situations. ${ }^{73}$ The court in that case basically seemed to say that unless there is a compelling reason for denying an individual access to such information, such access must be allowed. ${ }^{74}$

\section{Access and Accuracy of Information}

Authorized users access the data contained in the INSPECT system by simply signing into the online database and looking up the name of the individual. Information on the patient is then available for viewing immediately, with the only constraint being that there may be up to a seven day lag period for the input of new data. ${ }^{75}$ This input of new data is communicated to the INSPECT system by an authorized user simply uploading the data

72 NABP.NET, supra note 38 (adding that several other states have indicated an intent to join NABP InterConnect, which would bring the total to 22 states sharing data).

73 Williams v. State, 959 N.E.2d 360, 367 (Ind. Ct. App. 2012).

74 Id. at 368-369 ("Where, as here, a patient seeks to waive those privileges for the purpose of exercising his or her constitutional right to present a complete defense to charges in a criminal case, both the rationale for and the Board's interest in keeping the patient's prescription records confidential evaporate.").

75 BLUMENSCHEIN ET AL., supra note 33 , at 14-15. 
onto the database on-line. ${ }^{76}$ Implicit in the aforementioned information is that INSPECT only provides a prescription report to an authorized user upon request, making it a reactive system as opposed to a proactive one. Although developing a more proactive system is probably desirable, the INSPECT system is relatively up-to-date and easily accessible. While there are certainly aspects of INSPECT that can be improved upon, the program is among the best in the country in terms of ease of access and accuracy of information.

\section{Responsibilities and Liability Issues}

There are a number of responsibilities imposed upon dispensers of controlled substances covered by the INSPECT system. ${ }^{77}$ As mentioned briefly above, these responsibilities are basically in place to ensure that the data in the system reflects the quantity and identity of the drug a given individual has been prescribed. Other requirements imposed on dispensers help to ensure that the prescription data corresponds to the correct individual.78 Although clearly the INSPECT statutory scheme places significant responsibilities on dispensers, the same cannot be said with respect to physicians and other non-dispensing groups. ${ }^{79}$

Indiana law plainly states that all practitioners are under no obligation to reference the INSPECT database in writing any prescription to a given patient. ${ }^{80}$ Additionally, all practitioners are immune from civil liability for either consulting or failing to consult INSPECT information, even where such act or omission has resulted in the injury or death of an individual. ${ }^{81}$ There are three narrow exceptions to this statutory protection. One is that if a practitioner

\footnotetext{
$76 \quad I d$.

77 See IND. CoDE $\S 35-48-7-8.1$ (2012).

78 See id.

79 See id.; IND. CoDE § 35-48-7-2.9 (2012); INSPECT FAQs,
} IN.GOV, www.in.gov/pla/inspect/2371.htm (last visited May 20, 2013) (demonstrating that only dispensers are required to submit information to INSPECT, and there is no requirement for non-dispensers to do so).

80 IND. CODE $\S 35-48-7-11.1(\mathrm{k})(2012)$.

81 IND. CODE $§ 35-48-7 \cdot 11.1(1)(2012)$. 
receives direct information from the INSPECT system and negligently misuses it, there is a possibility for civil liability. ${ }^{82}$ The other two situations involve incidents of intentional misconduct by a practitioner. ${ }^{83}$ Such a broad scope of protection provided to practitioners probably indicates a legislative concern for avoiding the chilling effects on prescriptions discussed above. As mentioned, the legislature has made clear its intent to minimize INSPECT's impact on the treatment methods of practitioners in the state.

If a violation of Indiana's PMP laws is discovered, the punishment can be quite significant. In the realm of criminal liability, if the Board of Pharmacy believes that a violation has occurred, they may report relevant information to the appropriate authorities. ${ }^{84}$ A knowing or intentional violation of INSPECT legislation constitutes a Class A misdemeanor, ${ }^{85}$ which can carry a punishment of up to a year in prison, and up to a five-thousand-dollar fine. ${ }^{86}$ However, if such a violation has occurred in the context of a good faith disclosure of INSPECT information to law enforcement authorities, the practitioner is immune from both criminal and civil liability. ${ }^{87}$ In relaying information to law enforcement, all practitioners benefit from a legal presumption of good faith in their conduct. ${ }^{88}$

\section{ANALYSIS}

\section{A. Evaluating the INSPECT System}

The Indiana legislature has expressed two primary goals of the INSPECT system: providing patient information storage for health care professionals and providing a resource for controlled substance investigations of law

$\begin{array}{ll}82 & I d . \\ 83 & I d . \\ 84 & \text { IND. CODE } \S 35-48-7-11.1(\mathrm{~m}) \\ 85 & \text { IND. CODE } \S 35-48-7-14(2012) . \\ 86 & \text { IND. CODE } \S 35-50-3-2(2012) . \\ 87 & \text { IND. CODE } \S 35-48-7-11.1(\mathrm{n})(2012) . \\ 88 & I d .\end{array}$


enforcement without interfering with practitioners' treatment methods. ${ }^{89}$ Additionally, the National Alliance for Model State Drug Laws (NAMSDL), an entity focused on unifying state monitoring programs and providing standards that the states may refer to in developing their PMP laws, has articulated further goals that all state PMPs should seek to fulfill. ${ }^{90}$ Examining the INSPECT system while keeping all of these considerations in mind is an appropriate starting point in evaluating the efforts of the Indiana legislature in combating the drug abuse problem in the state.

\section{Detecting and Preventing Abuse and Misuse}

The first goal announced by NAMSDL is that of detecting and preventing abuse and misuse of prescription drugs covered by the PMP of a given state. ${ }^{91}$ As can be seen in Indiana's PMP laws and the aspects of the INSPECT system itself, this certainly seems to have been one of if not the central goal of the legislature and the program. ${ }^{92}$ Although the system is somewhat limited in that it produces reports on a reactive rather than a proactive basis, it still appears to provide enough information for authorized viewers to detect problematic prescriptions. The information that dispensers are required to submit to INSPECT provides authorized users with a valuable resource in recognizing such cases. ${ }^{93}$ Additionally, the fact that the information is relatively up to date, with the lag time for such information being no greater than seven days, helps to lessen the impact that the shortcomings of having a reactive system impose. ${ }^{94}$ Although the desire for even more up to date information is obvious, a maximum lag time

89 About INSPECT, supra note 59.

90 BLUMENSCHEIN ET AL., supra note 33 , at $3-4$; see also MODEL PMP, supra note 19.

91 BLUMENSCHEIN ET AL., supra note 33, at 3.

92 See generally IND. CODE $\S 35-48-7$ (2012).

93 See IND. CODE $\S 35-48-7-8.1$ (2012).

94 BLUMENSCHEIN ET AL., supra note 33, at 14-15. 
of just a week makes INSPECT among the most current in the country. ${ }^{95}$

Although Indiana is among the members of the National Association of Boards of Pharmacy's InterConnect program mentioned above, it is still somewhat limited in its ability to share prescription information across state lines. ${ }^{96}$ Obviously, the more states that a given PMP can share information with, the better situation that state's system will be in attempting to deter doctor shoppers crossing state lines. Therefore, continuing to achieve interoperability agreements should remain a priority in further developing INSPECT.

\section{Promoting Proper Use}

The NAMSDL also emphasizes the importance of states supporting the proper medical use of prescription drugs for which data is collected. ${ }^{97}$ This probably reflects the general concern for the chilling effects on physicians' willingness to prescribe drugs covered by PMPs for fear of liability. Some opponents go so far to say that this potential effect is so significant that it places doubt on whether states should be using them at all. The Indiana legislature too has recognized this risk, and as mentioned, has expressly stated that INSPECT is not meant to interfere with practitioners' abilities to treat patients in any respect. ${ }^{98}$ As further indication that the INSPECT system and its related legislation has taken the effects on treatment methods seriously, Indiana law completely shields practitioners from any type of liability in all but a few specific instances, clearly lending support to the notion that Indiana is attempting to promote the proper use of drugs covered by the system. ${ }^{99}$ However, when one considers that the incidents of drug abuse and misuse has continued to increase, it may be the case that such chilling effects are no

\footnotetext{
95 See id.

96 See NABP.NET, supra note 38.

97 BLUMENSCHEIN ET AL., supra note 33 , at 3.

98 About INSPECT, supra note 59.

99 IND. CODE $\S 35-48-7-11.1(1)$ (2012).
} 
more than a mistaken theory and that such sweeping protection over compensates for them. Such overcompensation may in turn limit the overall effectiveness of INSPECT and Indiana PMP laws.

\section{Informing the Public}

Several of the goals announced by the NAMSDL are related to informing and assisting the public with regard to prescription drug abuse and misuse. ${ }^{100}$ This generally involves helping persons addicted to monitored substances seek treatment for their addiction, using the data from the system to develop methods of educating the public about the dangers of monitored drugs, and educating the public, as well as practitioners, about PMPs and how they operate. ${ }^{101}$ Consistent with this NAMSDL objective, Indiana law allows for INSPECT data to be shared with certain substance abuse assistance programs. ${ }^{102}$ Additionally, the Indiana government has made a wide array of information pertaining to the dangers of prescription drugs, as well as information on the INSPECT system itself, available to the public through its official website. ${ }^{103}$

Although the information provided is unquestionably useful in achieving the goals related to public education on this issue, the continued prevalence of prescription drug abuse and misuse clearly demonstrates a need for even more effort in bringing this issue to the attention of the public. Currently, the information is available, but must be sought out by a given individual. Many may be oblivious to, or simply unwilling to utilize the availability of such information, and more must be done to bring this issue to the attention of the public, rather than simply expecting the public to seek such information out independently. The more that people know about the dangers of prescription drug use, and the ability of PMPs to detect abuse and

100 BLUMENSCHEIN ET AL., supra note 33, at 3-4.

101 Id.

102 IND. CODE ANN. § 35-48-7-11.1

103 See generally INSPECT Home, IN.GOV, www.in.gov/pla/inspect/ (last visited May 20, 2013). 
misuse, the more likely it is that they will be deterred from such use. Therefore, continued efforts in this area are crucial not only in Indiana, but nationally as well.

\section{Evaluation of Impact}

The NAMSDL model laws include a section that promotes the existence of some evaluative entity in an effort to gage the impact that a given PMP is having on battling prescription drug abuse and misuse. ${ }^{104}$ Such an entity would make annual findings related to cost-benefits of the program, overall impact on reducing prescription drug abuse, and impact on prescribing practices of practitioners, among other things. ${ }^{105}$ Indiana has not established such an entity, and no formal evaluation of the INSPECT program has yet been conducted. Establishing an evaluation process would allow INSPECT officials to identify areas for improvement, as well as areas that appear strong, with greater ease. Improving the program through this process would only serve to maximize the impact it has in combating prescription drug problems in Indiana.

\section{Overall}

In comparing the operation of the INSPECT system with the goals announced by the NAMSDL regarding state PMPs, it appears as if Indiana has held many of the mentioned concerns at the forefront of consideration. That being said, there still appears to be room for improvement. The data that has been collected in recent years indicates that prescription drug injuries and deaths have continued to increase across the country despite the efforts of entities like NAMSDL and state legislators, including those of Indiana, in developing PMP laws. ${ }^{106}$ Perhaps this suggests that new considerations and approaches must be taken in

104 MODEL PMP, supra note 19 , at $\S 12$ (suggesting that reports be submitted to several federal and state "decision makers" for review and the designated state agency produce an annual report for the public).

105 Id.

106 See generally Paulozzi, supra note 15; Girion, supra note 4. 
maximizing the ability of PMPs generally, and INSPECT specifically, to combat the prescription drug epidemic.

\section{B. Evaluation of Indiana PMP Laws}

Despite the relative quality of the INSPECT system, the full extent of the prescription drug problem in Indiana does not appear to be any less than is average among the states, particularly with respect to abuse and overdoses of prescription painkillers. ${ }^{107}$ This may be indicative of a potential problem in the governing legislation with regard to how the system is being utilized. This section will first examine the positive aspects of the Indiana law, and then identify some problematic areas.

\section{Some Positive Aspects}

The measures taken by the Indiana legislature ensure that the only groups authorized to view INSPECT data are those in a position to utilize it in furtherance of legitimate and substantial governmental interests in the area of public health and safety. ${ }^{108}$ Further, authorized groups have strict limitations imposed upon them with respect to whom they may disclose prescription data, ${ }^{109}$ and violating these limits may carry significant legal consequences. ${ }^{110}$ The information that is part of an INSPECT report is limited to that which is crucial for identifying the individual as well as whether or not there appears to be an issue regarding his or her prescriptions. ${ }^{111}$ Having an effective PMP while maintaining confidentiality of patient prescription records is one of the central concerns that NAMSDL has set forth, and this aspect of the Indiana law seems to have been centered on this consideration. ${ }^{112}$

107 See Paulozzi, supra note 10.

108 See IND. CODE ANN. § 35-48-7-11.1 (West 2012).

109 See id.

110 See IND. Code ANN. § 35-48-7-14 (West 2012).

111 See IND. CODE ANN. § 35-48-7-8.1 (West 2012).

112 See MODEL PMP, supra note 19, at $\$ 8$ ("Prescription monitoring information submitted to the [designated state agency or entity] 
Another positive aspect of the INSPECT legislation is that it encourages practitioners that have reason to believe that an individual may be abusing or misusing prescriptions to take positive action by shielding good faith disclosures to appropriate authorized entities from carrying any type of liability. ${ }^{113}$ Additionally, and as mentioned above, practitioners enjoy a presumption of good faith when such issues arise.114 Again, this is consistent with the goals set forth by NAMSDL and may be the best way to incentivize practitioners to make such disclosures when they believe that an individual is abusing prescription drugs. ${ }^{115}$

\section{Some Shortcomings in the Law}

Although there are clearly areas in which Indiana's approach to combating prescription drugs are strong, the fact remains that others require improvement if the effectiveness of INSPECT is to be maximized. The INSPECT system has the potential to provide an invaluable resource in combating drug abuse and misuse throughout the state. However, it may be the case that some of the PMP legislation currently in place is preventing the system from reaching the height of such potential.

NAMSDL suggests that state PMP laws should take into account the fact that many non-scheduled prescription substances are dangerous and abused with frequency. ${ }^{116}$ Aside from the fact that many non-scheduled substances are frequently abused, an additional problem is posed by the considerable risk of adverse drug interactions that many of these substances may create if taken in combination with other drugs, whether scheduled or not. Because of these considerations, it is suggested that in the case of many of these non-scheduled prescription drugs, PMP laws should

shall be confidential, is not subject to public or open record laws, and is not subject to disclosure or use except as provided in this section.").

113 IND. CODE ANN. § 35-48-7-11.1 (West 2012).

114 Id.

115 See BlumENSCHEIN ET AL., supra note 32, at 3-4.

$116 I d$. at 3. 
allow for data to be collected.117 Under its current PMP laws, Indiana's INSPECT program has absalutely no authority to collect data on such substances in any situation. ${ }^{118}$ Statutory authority to monitor non-scheduled substances in certain situations seems to be completely consistent with the over-arching goal of the state in detecting and preventing prescription drug abuse, so it seems surprising that Indiana law does not currently allow for any such data to be collected. Additionally, allowing for the monitoring of some non-scheduled substances would provide enhanced protection against innocent misuse of adversely reacting drugs. Although some may doubt the extent of the risk that such innocent misuse poses, allowing collection of such data could at the very least provide hard data useful in conclusively resolving the question of how much of an issue such misuse really is. All things considered, a change in Indiana PMP legislation allowing for monitoring of certain non-scheduled substances is desirable.

Perhaps the biggest problem with Indiana's current INSPECT legislation is that it does not impose any requirement that practitioners ever refer to the data stored in the system when writing a prescription. ${ }^{119}$ When this is coupled with the fact any type of liability can only attach if INSPECT data has been accessed in the first place, ${ }^{120}$ a glaring flaw in the current scheme comes into view. The scheme of the Indiana PMP laws effectively creates an incentive for practitioners to forget or remain oblivious to the fact that such a resource is even available to them. By failing to refer to the prescription data held in the INSPECT system at all, practitioners can essentially eliminate any prescription related claims against them, which are already extremely limited by the terms of the relevant statute. While it is certainly the case that many if not most prescriptions have potential for damaging side effects to patients and that practitioners should not

\footnotetext{
117 Id.

118 Id. at 8; see generally IND. CoDE ANN. § 35-48-7 (West 2012).

119 See IND. CODE ANN. § 35-48-7-11.1(k) (West 2012).

120 See IND. CODE ANN. $§ 35-48-7-11.1(\mathrm{~m})$ (West 2012).
} 
generally be held accountable for such risks, allowing prescribers to make these drugs available to patients without any regard for further dangers is inexcusable, especially considering the ease with which such information can be obtained through the use of the INSPECT system.

As discussed above, protecting practitioners from liability in certain situations is of great importance, not only to the viability of INSPECT and other PMPs, but to healthcare in general. One such situation relevant to INSPECT information would be the case of a good faith disclosure of prescription data regarding a belief that an individual is abusing or misusing prescription drugs. However, the extent of and approach to protection of practitioners under the current statutory scheme in Indiana may be limiting the effectiveness of INSPECT in achieving its maximum potential impact in combating the prescription drug epidemic in the state. Because of these limitations, it must be said that the language of the law is inconsistent with the express goals behind the INSPECT legislation. Not requiring practitioners to reference the INSPECT database in writing prescriptions creates a reasonable implication that the only real goal of the current PMP laws in Indiana is to aid in criminal investigations and prosecutions, and that any goals seemingly related to furthering public health are illusory.

\section{Recommendations for Change}

Having examined the shortcomings of both the INSPECT system itself and of its governing legislation, the issue becomes the feasibility of addressing these problems in an effort to maximize the program's effectiveness. Below are a number of key changes that can be made in Indiana that seem achievable and likely to help the INSPECT system reach its full potential. 


\section{Continue to Increase Number of Interoperability Agreements}

As mentioned above, Indiana's INSPECT system is one of a number of leading state PMPs in terms of sharing prescription data across state lines. ${ }^{121}$ Additionally, the official website of INSPECT has declared that Illinois and Kentucky will be added to the list of states Indiana shares such information with beginning sometime in 2013.122 Clearly this is a strong area of Indiana's PMP program and its related legislation. However, despite the fact that Indiana has made great strides in this area, more must continue to be done to ensure that interoperability can be achieved with as many states as possible. In a sense, this is not so much a recommendation for changes as it is a recommendation to take current efforts in this area even further in order to maximize Indiana practitioners' ability to identify cases of doctor shopping across state lines. This in turn will almost certainly cause significant positive impact in reducing prescription drug abuse and misuse throughout the state.

Obviously, the ideal scenario would allow for the Indiana system to exchange prescription data with any state. Considering that many states have PMPs that are only in the early stages of development, this seems to be a goal that remains out of reach for the immediate future. A much more realistic and achievable goal for the near future would be to reach agreements of interoperability with states that are in close proximity to Indiana. The fact that INSPECT data is already being shared with Ohio and Michigan, and will begin to be shared with Kentucky and Illinois in 2013, is obviously an excellent start, as it means that Indiana and all bordering states will be sharing prescription drug information in the near future. Having this ability to share data will all bordering states creates an enormous obstacle to what would presumably be a majority of potential interstate doctor shoppers who travel to nearby states, rather than distant ones, to obtain the amount of a given

121 NABP.NET, supra note 38.

122 About INSPECT, supra note 59 (click "Inspect At-A-Glance"). 
prescription they desire. However, the existence of such an obstacle will only create more incentive for these doctor shoppers to travel additional distances to other nearby states. Therefore, continuing to develop such interoperability agreements should remain at the forefront of goals for the further development of INSPECT moving into the future. If Indiana, and all states with operational PMPs for that matter, took measures to ensure that prescription information could be shared throughout a given region, this will eventually result in a nation wide web of systems that would severely limit, if not completely eliminate the ability of individuals to doctor shop across state lines.

\section{Develop a More Proactive System}

As mentioned briefly above, INSPECT is a reactive system, meaning that it produces reports on an individual patients prescription information only upon request from an authorized user of the system. ${ }^{123}$ It seems beyond any doubt that a more proactive system would be preferred to the current reactive one. Developing a proactive system that is capable of self-analyzing and identifying problematic prescription cases could greatly increase the efficiency of the INSPECT system. This could take at least part of the element of human error in interpreting a given prescription report produced by the system out of the equation. However, as stated, no state has of yet been able to develop a fully effective proactive system. It may be possible that this could be achieved by implementation of some type of analytical software package or similar technology that identifies and flags suspicious cases and brings them to the attention of authorized users based on certain characteristics frequently indicative of misuse of prescription drugs. This would in turn enhance the already considerable potential of INSPECT to successfully combat prescription drug abuse and misuse across the state. This certainly seems to be something that at the very least is

123 See generally IND. CODE ANN. § 35-48-7-8.1 (West 2012); see also BLUMENSCHEIN ET AL., supra note 33 at 14-15. 
worthy of consideration, but because no such system has yet been developed, it poses the question of whether such increase in the sophistication of the program would be cost prohibitive. This is explored below in the section related to cost effectiveness.

\section{Create an Independent Evaluative Entity}

As mentioned above, the NAMSDL recommends the creation of an evaluative entity to measure and report on the impact and effectiveness of PMPs on prescription drug abuse and misuse in a given state. ${ }^{124}$ While several states require the implementation of some type of advisory committee or other entity, Indiana is not currently among them. ${ }^{125}$ Creation of such an entity in Indiana would not only demonstrate the actual impact of INSPECT in combating the prescription drug problem, but also, it would help bring to light additional shortcomings of both the program and its governing legislation. The evaluative entity would have a number of responsibilities with respect to information related to the INSPECT system. For one, the entity could collect information from eligible users with an aim toward making the system as accessible and user friendly as possible. Additionally, the entity could collect annual data related to both prescription drug related deaths and arrests, and which drugs created the largest source of problems to determine how effective prior efforts had been in combating prescription drugs, and where future efforts should be focused. Creating such an entity could be of utmost utility in continuing to develop the INSPECT program in its ongoing battle against prescription drug abuse and misuse in Indiana moving into the future.

124 MODEL PMP, supra note 19 , at $\S 12$.

125 Nat'l Alliance for Model State Drug Laws, States that Mandate the Use of an Advisory Committee, Council, Task force, or Working Group (July 31, 2012), http://www.namsdl.org/documents/Statesthat MandatetheUseofanAdvisoryCommitteeetc07312012.pdf. It is worth noting that many of the states included on the map are those which Indiana shares prescription data with, whether through an independently achieved agreement of interoperability, or through the NABP InterConnect program. 


\section{Allow for Monitoring Non-Scheduled Substances}

Although clearly those scheduled substances which have been identified for their addictive and abusive tendencies pose what is probably the greatest risk to public health, this does not mean that they are the only threat. Nine states have legislation in place which allows for monitoring of nonscheduled substances under certain circumstances. ${ }^{126}$ Included amongst those states are Kansas, North Dakota, and Ohio, ${ }^{127}$ all states with which Indiana shares prescription information. While many of the states that have created such legislative authority have not yet begun to collect such data, the fact that the authority has been created demonstrates both that this is certainly a feasible notion and that this is a serious issue for which many states are seeking a remedy. In fact, it is suggested that the costs related to invasion of personal privacy are outweighed by the interests of monitoring such substances in some situations. Accordingly, the Indiana legislature should consider what situations might warrant such data collection.

There are at least three key situations in which the monitoring of non-scheduled prescription substances should be allowed under Indiana law. The first and probably most obvious scenario would be where the non-scheduled drug at issue has a tendency to be addictive or is abused with high frequency. This is consistent with the approach that NAMSDL recommends. ${ }^{128}$ A second situation would be one in which the non-scheduled drug at issue has a significant potential for dangerous drug interactions. Another alternative to this would be a law that allows for collection of any non-scheduled prescription data on an individual already taking more than 3 prescriptions, as this is the point at which the potential for such dangerous interactions drastically increases. ${ }^{129}$ The third situation would involve

126 See BLUMENSchein ET AL. supra note 33, at 8; see also NABP.NET, supra note 38 .

127 BLUMENSCHEIN ET AL. supra note 33 , at 8.

128 Id. at 3.

129 Avoiding Drug Interactions, supra note 24. 
individuals who voluntarily agree to have such information submitted in an attempt to enhance their protection against adverse drug interactions. It is important to note that none of the above suggestions are intended to affect the strict confidentiality and disclosure rules already in place. Additionally, the information that would be submitted to INSPECT under these proposed changes would already be collected for the records of the prescribers and dispensers, meaning any invasion of patient privacy is going to occur regardless of whether that information is then turned over to INSPECT. The INSPECT system simply provides a database on a much larger scale. Therefore, any further invasion to patient privacy as a result of these changes would be effectively negligible.

It should be noted with respect the second and third situations mentioned above that, although traditionally when we think about overdoses, we often assume that one drug is to blame, the reality is that a huge portion of deaths result from accidental drug interactions. ${ }^{130}$ As discussed above, a considerable percentage of the population in the U.S. takes more than four prescription drugs at any given time, while taking more than three prescriptions is said to drastically increase the chances of dangerous drug interactions. ${ }^{131}$ When one considers that there is ample data and literature illustrating the very real dangers of adverse drug interactions, the true weight of these numbers becomes hard to ignore. A significant portion of citizens in this country are consuming a dangerous amount of prescriptions, many of which we now know to interact adversely with one another. This is clearly an enormous threat to public health and yet it likely only begins to tell the whole story with respect to the dangers of taking so many prescriptions, as many if not most drug interactions are "discovered by accident and entirely too late - or are not discovered at all because people may not equate their

130 January W. Payne, A Dangerous Mix, WASH. Post, Feb. 27, 2007, at F01, available at http://www.washingtonpost.com/wp-dyn/ content/article/2007/02/23/AR2007022301780.html.

131 Avoiding Drug Interactions, supra note 24. 
symptoms to their medications."132 All things considered, until more is done to determine the full extent of the problems such interactions pose, the enormous amount of people taking a dangerous amount of prescriptions justifies making some efforts toward protecting against these risks, whether known or unknown.

\section{Require Practitioners to Consult the INSPECT Database}

Perhaps the biggest problem facing INSPECT in reaching its full potential in terms of impact on the prescription drug problem is simply the fact that it is not being used by enough Indiana practitioners on a regular basis. This is largely related to the fact that Indiana law places no requirement upon practitioners to reference the system before writing a prescription. ${ }^{133}$ According to the Director of INSPECT, Marty Allain, only somewhere around thirty-three percent of eligible physicians in the state are even registered to use the system. ${ }^{134}$ Considering that INSPECT is among the leading PMPs in the country and the first program to offer several key features, such as interstate sharing and data integration, ${ }^{135}$ it is remarkable that such a large percentage of physicians are not even registered to access its contents, let alone use them as an integral tool in the prescribing process. Because they are not required to use the information held within the system,

132 Joseph Mercola, Accidental Prescription Drug Deaths Spike Upward, MERCOLA.COM (Sept. 22, 2009), http://articles.mercola.com/ sites/articles/archive/2009/09/22/Accidental-Prescription-Drug-DeathsSpike-Upward.aspx.

133 IND. CODE ANN. $\S 35-48-7-11.1(\mathrm{k})$ (West 2012).

134 Marty Allain, OAG Task Force Subcommittee Update, Jan. 7, 2012 (A power point presentation created by $\mathrm{Mr}$. Allain listing percentages of other types of practitioners registered to use INSPECT: fifty-four percent of clinical nurse specialists; twenty-eight percent of CSR-certified nurse midwives; forty-four percent of CSR-osteopathic physicians; thirty-six percent of dentists; forty-six percent of nurse practitioners; twenty-nine percent of pharmacists; forty-one percent of physician assistants; and thirty one percent of podiatrists.)

135 E-mail from Marty Allain, Director, INSPECT, to Jacob O'Brien (Jan. 28, 2013) (on file with author). 
many practitioners in Indiana may not even be aware of exactly what INSPECT is, let alone what its goals are and how to use it effectively. With such an accessible and valuable resource in combating one of the most pervasive health issues facing Indiana, and the entire country, at their disposal, allowing practitioners to continue to approach treatment without ever even considering it is simply unacceptable. Although INSPECT enjoys the support of many of the practitioners who do use the system, many of whom advocate the furtherance of its use, this alone is not enough to implement they system to its full extent. So long as there is no legal requirement to check INSPECT in writing a prescription, the system will never reach its full potential, and the immense benefits that the Indiana legislature aspired to in developing the program will never be realized.

There are currently twelve states with legislation in place requiring prescribers and dispensers to access PMP information in certain circumstances. ${ }^{136}$ For several of these states, this is a new component of their respective PMP legislation, and will become effective beginning in 2013.137 One approach in such legislation is to require prescribers and dispensers to examine prescription data related to a prior twelve month period before completing such a transaction. ${ }^{138}$

Interestingly, during the drafting of this note, a bill was introduced before the Indiana legislature that would have added Indiana to the list of states that require healthcare practitioners to reference PMP data before prescribing, dispensing, or administering a controlled substance. ${ }^{139}$

136 Nat'l Alliance for Model State Drug Laws, States that Require Prescribers and/or Dispensers to Access PMP information in Certain Circumstances (Sept. 12, 2012), http://www.namsdl.org/

documents/StatesthatRequirePractitionerstoAccessinCertainCircum stances09122012.pdf.

137 Id.

138 BLUMENSCHEIN ET AL., supra note 33, at 9 (discussing Nevada's approach).

139 H.B. 1465, 118 th Gen. Assemb., Reg. Sess. (Ind. 2013), available at $\mathrm{http} / / / \mathrm{www} . \mathrm{in} . g 0 v /$ legislative/bills/2013/IN/IN1465.1.html (as introduced on Jan. 22, 2013). 
Specifically, the bill proposed to require such a practitioner to use INSPECT prior to taking the given action when the amount of the substance given "exceeds a thirty day supply for treatment of a patient." 140 However, the bill did not squarely address the consequences that would follow from a failure to observe this reporting procedure. ${ }^{141}$ Presumably, the general provisions regarding violation of INSPECT laws would apply, meaning that failure to comply could have constituted a Class A misdemeanor. ${ }^{142}$

Adopting this requirements would obviously have been a huge step towards maximizing the ability of INSPECT to combat prescription drug abuse and misuse in Indiana. ${ }^{143}$ The INSPECT system is an enormous resource that can have great impact in combating the public health nightmare that prescription drug abuse has created, and failure to use this information that is so easily and readily accessible is simply unacceptable. Holding practitioners accountable for failure to use such a valuable tool would simply be a reflection of the fact that society expects providers of healthcare to make decisions related to individual patients based on all relevant and available information. Anything short of that should simply be recognized for what it is: clear neglect of occupational and professional duty.

Because the INSPECT system can only be of utility if it is actually being used, I would suggest development of legislation that at the very least requires the approach discussed above regarding states that require practitioners and dispensers to reference PMP information, as well as the bill that is currently being discussed in the Indiana legislature. Tracking whether a required individual referenced the appropriate data would be as simple as creating an access log within the INSPECT system that

$140 I d$.

141 Id.

142 See IND. CODE ANN. $\S 35-48-7-11.1$ (West 2012); IND. CoDE ANN. $\S 35-50-3-2$ (West 2012).

143 While the bill was ultimately enacted, substantial amendments were made during the legislative process that resulted in the removal of the referencing requirement. See H.B. 1465, 118 ${ }^{\text {th }}$ Gen. Assemb. Reg. Sess. (Ind. 2013) (enrolled act), available at http://www.in.gov/ legislative/bills/2013/HE/HE1465.1.html. 
would show when such a user accessed the system, and requiring that this information also be included as part of the prescribing transaction and submitted to the inspect system. Failure on the part of a practitioner to consult the system should result in subjecting him/her to liability where such failure results in injury or death. Immunity should otherwise be preserved as established by current Indiana law. In other words, so long as a practitioner consults the system, examines its data in good faith, and does not engage in conduct that would subject him/her to liability under current Indiana law, he should be deemed immune from suit.

Opponents to this approach would likely condemn it as an enhancement of the feared chilling effects that PMPs and associated legislation can have, as discussed above. As much of this paper demonstrates, any fear or chilling effects appears to be simply unfounded. More prescription drugs are still being produced every year than in the preceding year, and deaths from prescriptions have continued to rise. The drugs would not be as readily available as necessary for such impact if the supposed chilling effect were having any significant impact on practitioners. Another possibility to consider is that enhancing any type of chilling effect on practitioners in how they write prescriptions may not be all bad. As discussed earlier, a substantial portion of people are prescribed a dangerous amount of prescriptions. Perhaps forcing practitioners to exercise more discretion before they pull out their prescription pad may be a good thing, and could result in reducing this number. In turn, this would reduce the risk that such drugs pose to patients. The INSPECT system has the potential to make an enormous impact in combating the prescription drug problem in Indiana, but this can only be achieved if the system is actually being put to use by practitioners in the state. The proposed approach is a reasonable and achievable means of helping the utility of the system reach its optimal level. 


\section{Cost Effectiveness}

Obviously, most if not all of the recommendations made above with respect to improving the INSPECT system and its governing legislation could potentially lead to additional costs in the operation of the system. It is difficult to predict exactly what the extent of these additional costs would be, and such price determinations with respect to those costs are beyond the scope of this note. However, it is also clear that a discussion of the viability of making such improvements to the INSPECT system cannot be complete without considering such costs, at least to some degree.

To begin the discussion of adding additional costs to the operation of INSPECT, one must first have some idea of the current cost and how it compares with other states. In looking at the normal range of funding costs for PMPs, it appears that even the most expensive programs have annual budgets no greater than one million dollars. ${ }^{144}$ When one considers the enormity of overall state budgets, it must be said that PMPs are operated at relatively low cost. Indiana's budget for INSPECT is around $\$ 450,000$ annually. ${ }^{145}$ The average budget for states with a population of three-and-a-half million or greater is $\$ 607,000$, and the average budget for the states surrounding Indiana is $\$ 927,350$, clearly illustrating that the costs of operating INSPECT are relatively low when compared with similarly situated state programs. ${ }^{146}$

Additionally, INSPECT receives significant federal funding from the Harold Rogers grant program related to assisting states in operating PMPs. ${ }^{147}$ In fact, it appears as if around three fourths of INSPECT's budget comes from such federal grants. ${ }^{148}$ This serves to minimize the amount

144 BLUMENSCHEIN ET AL., supra note 33, at 10; see also Marty Allain, OAG Task Force Subcommittee Update, Jan. 7, 2012 (a power point presentation created by Mr. Allain).

145 Marty Allain, Director, INSPECT, OAG Task Force Subcommittee Update (Jan. 7, 2012).

$146 \mathrm{Id}$.

147 About INSPECT, supra note 59.

148 Allain, supra note 145. There has been some suggestion during the drafting of this note that the Federal funds made available through 
of Indiana money that is required for the operation of the system. The remainder of the funding is currently sourced in a percentage of state controlled substance registration fees. ${ }^{149}$ However, in the same bill discussed above that would have required practitioners to use INSPECT, it was proposed that, instead of taking merely a percentage of such controlled substance registration fees, the entire amount would be included in the INSPECT budget. ${ }^{150}$ This portion of the bill survived and becomes effective July 1, 2013.151 These additional funds may allow for such recommendations as laid forth above to become readily achievable without having to create further sources of funding.

Another important consideration in assessing whether additional costs associated with the operation of INSPECT would be justified is the enormous cost already being paid related to prescription drug abuse. For example, there is ample data to suggest that abuse rates of prescription drugs are highest in low-income, Medicaid-dependent demographics. ${ }^{152}$ When one considers that government money is currently being indirectly used to support the addictions to prescriptions of many people, the net effect of broadening the scope of INSPECT by incorporating the suggestions above might actually be to reduce the overall costs associated with prescription drug abuse and misuse. Even if more state funds were to be required, it seems unlikely that the costs would render such improvement of the program unattainable. The potential impact that

the Harold Rogers program may be reduced or eliminated entirely in the not so distant future. If this becomes a reality, then the bill currently being considered would become vital to the continued success and development of the INSPECT program.)

149 About INSPECT, supra note 59.

150 H.B. 1465, $118^{\text {th }}$ Gen. Assemb. Reg. Sess. (Ind. 2013), available at http://www.in.gov/legislative/bills/2013/IN/IN1465.1.html (as introduced on Jan. 22, 2013).

151 H.B. 1465, 118 ${ }^{\text {th }}$ Gen. Assemb. Reg. Sess. (Ind. 2013) (enrolled act), available at http://www.in.gov/legislative/bills/2013/HE/HE1465.1. html.

152 Ass'N OF ST. AND TERRITORIAL HEALTH OFFICIALS, PRESCRIPTION DRUG OVERDOSE: STATE HEALTH AGENCIES RESPOND 4 (2008), available at http://www.cdc.gov/HomeandRecreationalSafety/pubs/RXReport_web-a.pdf. 
improving the system in the various ways mentioned above could have on the effectiveness of this already valuable resource may very well justify any additional costs. At the very least, the suggestions made above as well as ways to fund them should continue to be explored moving into the future.

\section{CONCLUSION}

The measures taken by the Indiana legislature in developing the INSPECT system have created a valuable foundation for combating the prescription drug problem in the state. While the system is relatively strong when compared to PMPs of other states, there remain a number of shortcomings in both the system itself and its governing legislation. These shortcomings are preventing INSPECT from reaching its full potential in terms of bringing this problem under control. The suggested changes to Indiana PMP legislation made in this paper provide reasonable means of ensuring that INSPECT continues to advance toward reaching its full utilitarian potential. 
